\title{
FOOT POSTURE ASSESSMENT IN TRAFFIC POLICEMEN
}

\section{Arnaaz Rusi Doctor*, Shweta Satish Devare Phadke.}

D.Y Patil University, School of Physiotherapy, Nerul, Navi Mumbai, Maharashtra, India.

\section{ABSTRACT}

Background: Adult flatfoot is defined as a foot condition that persists or develops after skeletal maturity and is characterized by partial or complete loss or collapse of medial longitudinal arch. As traffic police officers have long standing hours on duty, wear improper footwear and have a higher BMI therefore this study was undertaken to assess foot posture in traffic policemen.

Purpose of the study: Aim of this study is to assess the arches of foot in traffic policemen and objective is to study the effect of BMI and long static standing duty hours on medial arch of foot.

Methodology: A cross sectional study was conducted in Navi Mumbai Traffic police chowki's on 200 traffic policemen. Outcome of the study that is navicular drop test were assessed for each subject.

Results: In our study 81 subjects were between $41-50$ years of age and $92 \%$ subjects were males. Maximum subjects (70) had a height between $166-170 \mathrm{cms}$ and 110 subjects were overweight with BMI between 25-29.9. Prevalence of flat feet in our study population was $34 \%$ in left foot and $33 \%$ in right foot. The mean navicular drop difference in right foot was 7.53 and 7.74 in left foot. There was a positive correlation seen between BMI and right foot navicular distance difference and left foot navicular distance difference respectively.

Conclusion: Prevalence of flat feet was only 34\%. The high BMI has an adverse effect on the medial arch of foot in the traffic policemen.

Key words: Flat Foot, Navicular Drop Test.

Address for correspondence: Dr. Arnaaz Rusi Doctor, D.Y Patil University, School of Physiotherapy, Sector 7, Nerul, Navi Mumbai 400706, Maharashtra, India. E-Mail: arnaazd@gmail.com

\begin{tabular}{|c|c|c|}
\hline \multicolumn{3}{|c|}{ Access this Article online } \\
\hline Quick Response code & \multicolumn{2}{|c|}{$\begin{array}{l}\text { International Journal of Physiotherapy and Research } \\
\text { ISSN 2321- } 1822 \\
\text { www.ijmhr.org/ijpr.html }\end{array}$} \\
\hline DoI: $10.16965 /$ ijpr.2017.181 & $\begin{array}{l}\text { Received: 31-05-2017 } \\
\text { Peer Review: 01-06-2017 } \\
\text { Revised: None }\end{array}$ & $\begin{array}{l}\text { Accepted: } 19-06-2017 \\
\text { Published (O): 11-08-2017 } \\
\text { Published (P): 11-08-2017 }\end{array}$ \\
\hline
\end{tabular}

\section{INTRODUCTION}

According to World Health Organization (WHO), occupational health is defined as "The promotion and maintenance of the highest degree of physical, mental and social well-being of workers in all occupations by preventing departures from health, controlling risks and the adaption of work to people, and people to their jobs." [1]. Traffic police officers have a high risk job as said by Driscoll et al. They also have many health related issues due to their occupation. Mostly their physical health is affected because of their long hours of standing duty on the road, exposure to sun and cold, constant travelling on bike throughout the day [2]. It is observed that traffic police officers who are on the streets everyday are prone to developing varicose veins of lower limbs due to damage of valves. This leads to swelling and lot of discomfort. They are also prone to joint problems and photosensitivity due to long hour exposure in sun. The unhealthy diet and irregular eating time and lack of exercise make them obese and the long static standing hours makes their body stiff. Improper footwear they use also causes foot posture related problems especially as they require to stand for long hours [3].

Pesplanus (flatfoot) is one of the most common 
conditions observed in adult health practice. The true prevalence of flatfoot is unknown, mainly because there is no such clinical or radiographic criteria for defining a flatfoot. Adult flatfoot is defined as a foot condition that persists or develops after skeletal maturity and is characterized by partial or complete loss or collapse of medial longitudinal arch. Adult flatfoot may present as an incidental finding or as a symptomatic condition with clinical consequences ranging from mild limitations to severe disability and pain causing major impediments. The adult flatfoot is often a complex disorder with variety of symptoms and various degrees of deformity. Pathology and symptoms are caused by structural loading changes along the medial foot and plantar arch, as well as by collapse through the midfoot and impingement along the lateral column andrearfoot. Muscles in the leg and foot tend to fatigue and cramp because of overuse [4].

Although obesity and overweight is a temporary, but it can be the cause of flatfoot. The foot adapts itself under loading condition by maintaining the medial longitudinal arch. Increasing the loading further activates compensatory mechanisms which maintain the longitudinal arch and shifts the loads to the central and medial forefoot [5].

Navicular Drop Test is a common method for assessing prevalence of flatfoot.

As traffic police officers have long static standing hours on duty, wear improper footwear and have a higher BMI therefore this study was undertaken to assess the effect of BMI and long static standing hours duty on medial arch of foot in traffic policemen.

\section{MATERIALS AND METHODS}

The study set up for this project was Traffic police chowki's in Navi Mumbai. This study is a cross sectional survey carried out on 200 traffic policemen of navi Mumbai excluding policemen who were on leave or suffering from foot injuries.

The study procedure for this study was as follows. Permission was taken to conduct medial arch assessment for traffic policemen through administrator, Navi Mumbai traffic policemen department. Demographic details such as Gender and age were recorded and also weight and height was taken to calculate Body Mass Index for each individual. Weight was taken with and without gadgets. After that Navicular drop test was performed to assess the medial arch of the foot.

For checking Navicular drop test, the subject is first positioned in standing i.e weight bearing position. Using a small rigid ruler, the height of the navicular bone was measured from the floor to the most prominent part of navicular tuberosity when in the neutral talar position. Again the height of the navicular bone is measured in sitting position i.e non weight bearing position. The difference in measurement is the navicular drop and drop $>/=10 \mathrm{~mm}$ will be regarded as pesplanus [6-8].

For statistical analysis unpaired t test was used for Navicular distance difference between left and right foot and Pearson's correlation of BMI with right foot and left foot navicular distance difference.

\section{RESULT AND DISCUSSION}

This study was designed to assess the medial arch of foot in traffic policemen. We had taken permission from the DCP to conduct this study. 200 traffic policemen from various police chowki's in Navi Mumbai had participated in this study.

Graph 1: Showing the Age Distribution in the study.

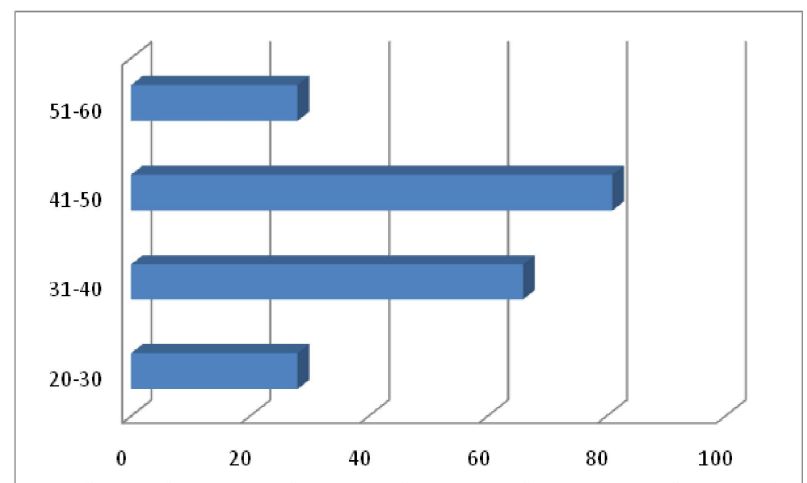

Graph 2: Showing the Gender Distribution in the study.

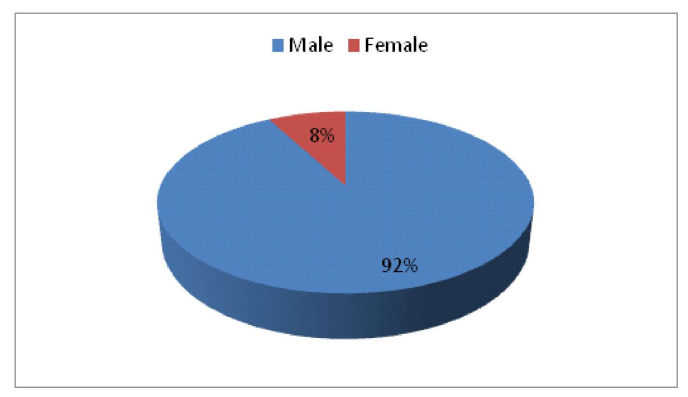


As seen in Graph 1, it shows the age distribution in our study. Out of 200 subjects, majority of our subjects that is 81 subjects were between 41-50 years of age. It is also seen that we had $92 \%$ of male subjects as shown in Graph 2.

We assesed their weight and height to calculate the Body Mass Index.The effect of BMI on medial arch of foot was observed. We took weight without and with gadgets as we observe on duty traffic policemen have to wear the gadgets which add weight. The mean of weight with gadgets for the subjects was 79.73 and for weight without gadgets was 78.16 . Thus the mean difference in the weights was $1.57 \mathrm{~kg}$ which is significant enough to alter biomechanics of the body.

Graph 3: Showing the Height Distribution in the study.

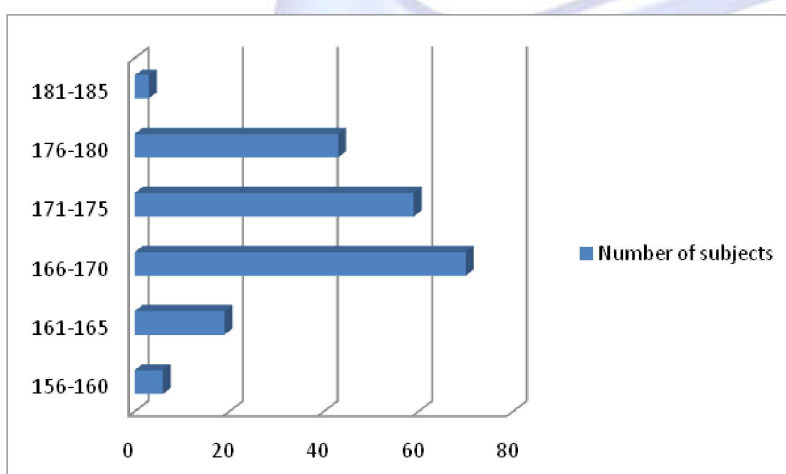

As seen in Graph 3, the height distribution in our subjects in centimeters. 70 subjects had a height between $166-170 \mathrm{cms}$ and 59 subjects were between $171-175 \mathrm{cms}$.

Graph 4: Showing the Body Mass Index Distribution in the study.

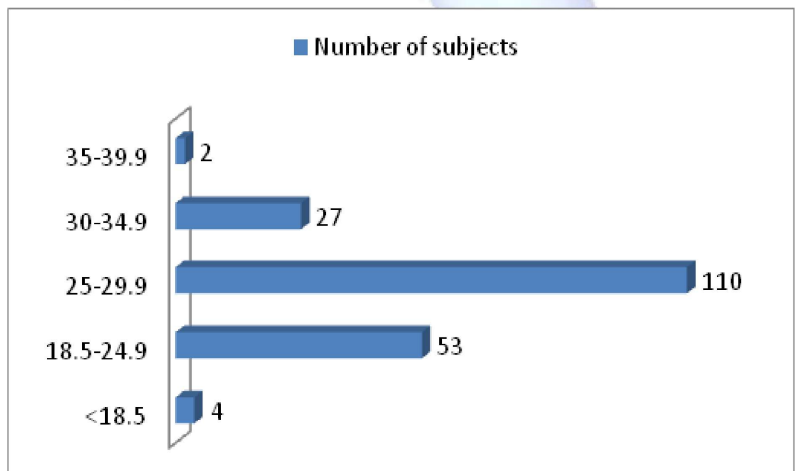

Graph 4 shows Body Mass Index distribution in our study. It was seen that maximum subjects that is 110 were overweight who had BMI between 25 and 29.9 .

Studies showed that the BMI was associated with flat foot. This can be associated with excessive belly fat causing weak abdominals and in turn causing excessive lordotic posture. and transfer of force through foot. As a result the weight bearing areas are changed. Along with this decreased muscle strength which also causes collapsed arches [5].

Graph 5: Reduced Navicular Distance Difference in right and left foot.

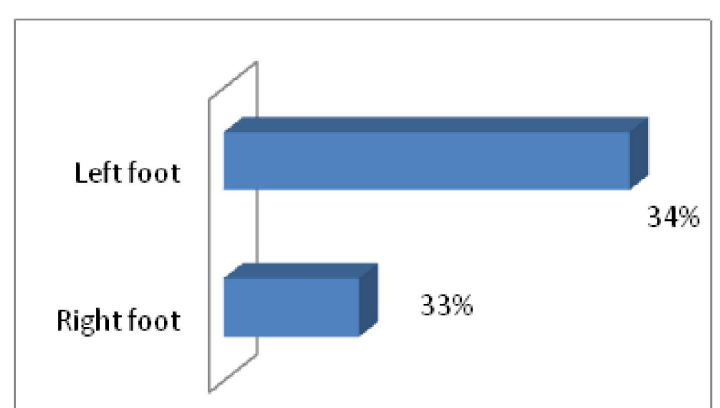

We have used Navicular Drop Test to assess the medial arch of foot. As seen in Graph 5, 33\% of subjects in our study had reduced navicular distance difference in right foot whereas 34\% of subjects in our study had reduced navicular distance in left foot. Table 1 shows that 68 and 66 subjects in our study have reduced navicular distance difference.

Table 1: Distribution of subjects with positive navicular distance in right and left foot.

\begin{tabular}{|c|c|c|}
\hline & Left Foot & Right Foot \\
\hline Number of subjects with positive navicular test & 68 & 66 \\
\hline Percentage & $34 \%$ & $33 \%$ \\
\hline
\end{tabular}

Table 2: Shows that when statistical analysis done with unpaired t test for the navicular distance difference, the result was not statistically significant.

\begin{tabular}{|c|c|c|}
\hline Group & $\begin{array}{c}\text { Right foot navicular } \\
\text { drop diff }\end{array}$ & $\begin{array}{c}\text { left foot } \\
\text { navicular drop diff }\end{array}$ \\
\hline Mean & 7.53 & 7.74 \\
\hline SD & 4.31 & 4.29 \\
\hline SEM & 0.32 & 0.32 \\
\hline N & 186 & 182 \\
\hline
\end{tabular}

Graph 6: Pearson's Correlation of BMI with Right Foot Navicular distance difference.

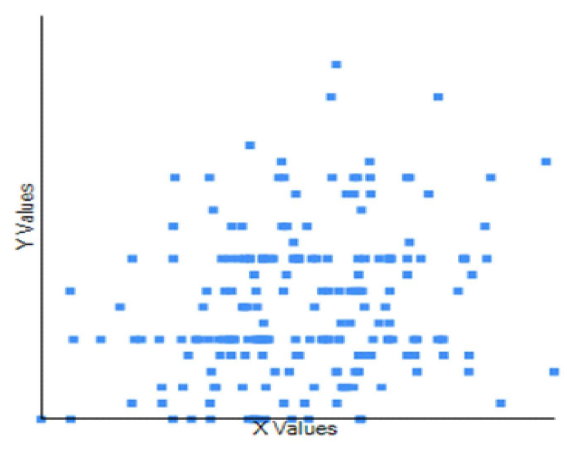

X-BMI

Y- Right foot navicular distance difference 
Statistical Analysis: Unpaired T test done for Navicular distance difference between left and right foot.

Pearson's correlation was done of BMI with right and left foot navicular distance difference as seen in Graph 6 and 7. The value of $R$ was 0.2131 for Graph 6 and 0.1108 for Graph 7.

Graph 7: Pearson's Correlation of BMI with Left Foot Navicular distance difference.

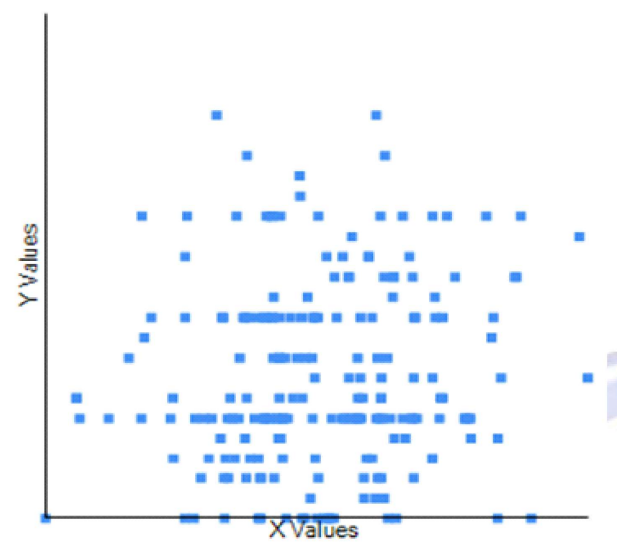

$\mathrm{X}-\mathrm{BMI}$

Y- Left foot navicular distance difference

According to Pearson's correlation although there was a positive correlation between BMI and left and right foot navicular distance difference, the relation between the variables was weak.The present study shows the effect of BMI on Medial arch of foot, due to high BMI there is reduced navicular distance difference.

\section{CONCLUSION}

Prevalence of flat feet was only $34 \%$. The high BMI has an adverse effect on the medial arch of foot in the traffic policemen.

The conclusion of this study is that the high BMI has an adverse effect on the medial arch of foot in the traffic policemen. Due to long standing static on duty hours with gadgets there is excessive pressure on the foot which can be the reason for the reduced navicular distance difference seen in our study.

\section{Conflicts of interest: None}

\section{REFERENCES}

[1]. http://www.agius.com/hew/resource/ohsilo.htm

[2]. Driscoll, T. Mitchell, R. Mandryk, J Healey, S \& Hendric, Work related Traumatic facilities in Australia, Australian institute of criminology, L. 1999, 1989 to 1992, NOHSC, Ausinfo, Canbera.

[3]. http://kathmandupost.ekantipur.com/printedition/ news/2012-03-11/occupational-hazards-for-traffic-police-officers.html

[4]. Tejashree Bhoir, Dr Deepak Anap, Dr Abhijit Diwate, Prevalence of flat foot among 18-25 years old physiotherapy students: Cross sectional study.Indian Journal Of Basic \& applied medical research; Sept 2014;3(4):272-273.

[5]. Ashwini Chougala, Vidit Phanse, E. Khanna, Sudipta Panda, Screening of Body Mass Index \& functional flatfoot in adult: An observational study. International Journal of Physiotherapy \& Research 2015;3(3):1037-41. ISSN 2321-1822.

[6]. Rasmus G Nielsen, Michael S Rathleff, Ole H Simonsen and Henning Langberg et al Determination of normal values for navicular drop during walking: a new model correcting for foot length and gender Journal of Foot and Ankle Research 2009;2:12 doi:10.1186/1757-1146-2-12.

[7]. MetteKjærgaard Nilsson, Rikke Friis, Maria Skjoldahl Michaelsen, Patrick Abildgaard Jakobsen and Rasmus Oestergaard Nielsen et al Classification of the height and flexibility of the medial longitudinal arch of the foot Nilsson et al. Journal of Foot and Ankle Research 2012;5:3

[8]. Picciano AM, Rowland MS, worrel Reliabilty of open \& close kinetic chain subtalar joint neutral position \& navicular drop test. Jorthop sport phys. Ther, 1993;18:553-558.

[9]. For statistical calculations :

https://www.graphpad.com/quickcalcs/ttest1.cfm http://www.socscistatistics.com/tests/pearson/ Default2.aspx

How to cite this article:

Arnaaz Rusi Doctor, Shweta Satish Devare Phadke. FOOT POSTURE ASSESSMENT IN TRAFFIC POLICEMEN. Int J Physiother Res 2017;5(4):22492252. DOI: $10.16965 /$ ijpr.2017.181 